\title{
Effects of relative humidity on ethanol vapour releases from hydrophilic film- based sachet in active food packaging
}

\author{
${ }^{1}$ Kampawong, H., ${ }^{1,3, *}$ Utto, W. and ${ }^{2}$ Pruthtikul, R. \\ ${ }^{1}$ Department of Agro-Industry, Faculty of Agriculture, Ubon Ratchathani University, Ubon Ratchathani, \\ 34190, Thailand \\ ${ }^{2}$ National Metal and Materials Technology (MTEC), National Science and Technology Development Agency \\ (NSTDA), Pathum Thani, 12120, Thailand \\ ${ }^{3}$ Postharvest Technology Innovation Center, Commission on Higher Education, Bangkok, 10400, Thailand
}

\section{Article history:}

Received: 26 March 2021

Received in revised form: 27 April 2021

Accepted: 10 July 2021

Available Online: 19

September 2021

\section{Keywords:}

Sachet,

Hydrophilic film,

Active packaging,

Ethylene vinyl acetate

(EVA),

Nylon/PE,

Relative humidity

DOI:

https://doi.org/10.26656/fr.2017.5(5).202

\begin{abstract}
Active food package incorporating an ethanol vapour-controlled release sachet has been known for its efficacies to delay microbial proliferation in fresh fruit and vegetable. High humidity inside the package could be utilized as a stimulus for conditional releases as a means to stabilize the sachet prior to being used. The present research was undertaken to investigate the effects of relative humidity on ethanol vapour release from the hydrophilic film-based sachet. The prototype 4-side sealed sachets were made of either ethylene vinyl acetate (EVA) or laminated film comprising EVA and Nylon/PE (designated as ENP). A gas chromatogram equipped with a flame-ionized detector (FID-GC) was employed to analyze ethanol vapour concentration levels released from both sachet types and accumulated in headspaces of sealed glass beakers having different relative humidity $(\mathrm{RH})$ levels. For a given RH level, the concentrations in the headspaces containing the ENPbased sachets were lower than those containing the EVA-based sachets. Delays of ethanol vapour release up to $24 \mathrm{~h}$ were observed in the ENP-based sachet system, whilst these did not occur among EVA-based sachets. Both sachets could release ethanol vapour with faster rates and subsequently higher concentrations accumulated at the very high relative humidity level $(90-99 \% \mathrm{RH})$, compared to lower RH levels $(60-89 \% \mathrm{RH})$. However, the release rates and concentration levels accumulated in $60-75 \% \mathrm{RH}$ were not different from those in $80-89 \%$ RH. Extents of water vapour uptake by films were relatively small when the films were kept at the lower RH levels, but these became exponentially increased when the RH levels were $\geq 90 \% \mathrm{RH}$. Experimental data on water vapour uptakes were well predicted by an exponential model $\left(\mathrm{R}^{2}\right.$ 0.92-0.99; and root mean square of errors (RMSE) 0.004-0.054). Overall, experiment findings indicate that the ENP film caused delayed ethanol vapour releases from the sachet. The relative humidity levels had significant effects on the releases from hydrophilic film-based sachets.
\end{abstract}

\section{Introduction}

Modified atmosphere packaging systems (MAP, commonly known as passive MAP) have been used for packing fresh fruit and vegetables because of their simplicities and technical applications in slowing down quality changes (Malakar et al., 2020). Counterbalances between gaseous permeation through the film as a key packaging material and respirations of horticultural products cause modifications of gaseous concentrations (reduced $\mathrm{O}_{2}$ and increased $\mathrm{CO}_{2}$ concentration) and high humidity level inside the package, compared to those in an ambient (Kader et al., 1989; Fonseca et al., 2002).
There are increasing interests in incorporated ethanol vapour-controlled release sachet into the package. The ethanol vapour slowly is released from the sachet to package headspace, and subsequently interacts with the fresh produce packaging. The interactions subsequently lower microbial proliferation and other qualities including colour and aroma volatiles (Utto, 2014). Ethanol is categorized as generally recognized as safe (GRAS) which is considered safe for consumers. Applications of ethanol vapour-controlled release sachets were tested and reported in a range of fresh fruit and vegetable including sweet cherries (Bai et al., 2011), freshly peeled shallots (Utto et al., 2018), cherry 
tomatoes (Kampawong et al., 2018) and mulberry (Choosung et al., 2019).

Key limitations are instant releases of ethanol vapour from the sachet after prepared (Utto, 2014). Such releasing behaviour could reduce amounts of ethanol left on carriers within the sachet. This potentially lowers the efficacies of the active system to interact with microorganisms throughout the desired storage period (Utto et al., 2005). We accordingly became interested in developing the sachet having abilities to release ethanol vapours under a certain condition. The condition of interest is the very high relative humidity $95-99 \% \mathrm{RH}$ typically happened inside the passive MAP (Kader et al., 1989). Because the high humidity can facilitate microbial growth, releasing the ethanol vapour under this condition would expectedly minimize as well as delay the growth. To develop the sachet noted, hydrophilic plastic films were utilized as sachet materials. The films easily interact with moisture via absorbing into its structure leading to increases in its structural free volume or socalled the plasticization effect (Siracusa, 2012; Robertson, 2012). This effect facilitates absorbed molecule diffuses inside the polymeric structure with faster rates compared to when the film is under a dried condition (Johansson and Leufvén, 1994). By using the hydrophilic film which is a high barrier to ethanol vapour under the dried condition but becomes highly permeable under high humidity should be considered an ideal sachet material to minimize instant ethanol vapour releases from the sachet. There has not been any report on the sachet development using hydrophilic film as well as using high moisture as a release stimulus. In the present work, the research objectives were to develop a prototype of the hydrophilic film-based sachet, to investigate releases of ethanol vapour from the sachets in relation to relative humidity levels.

\section{Materials and methods}

\subsection{Hydrophilic film material}

Hydrophilic films were utilized as sachet materials i.e., EVA (154.50 $\mu \mathrm{m}$ thickness) and laminated Nylon film (Nylon/PE; $83.67 \mu \mathrm{m}$ thickness). It should be noted that the Nylon per se is hydrophilic, but PE is not. PE layer was laminated to the Nylon one for the heat-sealing purpose. Key EVA film's properties including $\mathrm{O}_{2}$ transmission rate (OTR) (OTR Tester, OXTRAN $^{\mathrm{O}}$ model $1 / 50$, MOCON, USA), $\mathrm{CO}_{2}$ transmission rate (CTR) (PERMATRAN-C $®$ model 4/41 Module MCT, MOCON, USA) and water vapour transmission rate (WVTR) (Water vapour permeation analyzer, 7002, Illinois Instruments, USA) were $2256 \mathrm{~mL} / \mathrm{m}^{2} /$ day, $8,181.24 \mathrm{~mL} / \mathrm{m}^{2} /$ day and $10.47 \mathrm{~g} / \mathrm{m}^{2} /$ day, respectively. Meanwhile these properties of Nylon/PE film, in the same order, were $28.88 \mathrm{~mL} / \mathrm{m}^{2} /$ day, $181.44 \mathrm{~mL} / \mathrm{m}^{2} /$ day and $5.29 \mathrm{~g} / \mathrm{m}^{2} /$ day, respectively.

\subsection{Ethanol vapour-controlled release sachet preparation}

\subsubsection{Conceptual model of the hydrophilic film-} based sachet

The ethanol vapour-controlled release sachet of which its materials were made of the hydrophilic films was developed regarding the conceptual model shown in Figure 1-A. A sachet material is structurally comprised of 2 layers including (from outside) EVA film and Nylon/PE. When formed as a sachet, the PE layer immediately contacts with ethanol liquid pre-adsorbed on filter paper (as an ethanol liquid carrier). In a study by Utto et al. (2016), Nylon/PE reportedly was a moderately high barrier film to ethanol vapour. The Nylon/PE layer principally should slow down ethanol vapour released out from the paper, under low humidity levels. When the humidity surrounding the sachet increased, the EVA layer adsorbs water vapour molecules into its polymeric structure (Figure 1-B). The adsorbed molecules later increase the free volumes inside the polymeric structure, subsequently causing the plasticization effect. Given such effect, the ethanol molecule adsorbed into the EVA layer (i.e., after desorbed out from Nylon/PE layer) could permeate through the EVA layer with faster rates. The processes hence stimulate releases of ethanol vapour from the sachet (Figure 1-B). In addition, the water molecules adsorbed into the EVA layer were assumed to diffuse into the Nylon layer in which the plasticization effect was also expected, causing higher rates of ethanol vapour to permeate from the sachet.

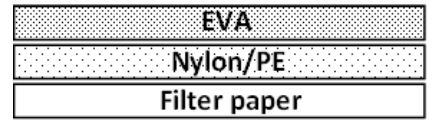

(A)

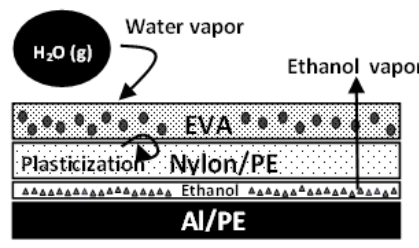

(B)
Figure 1. Conceptual model of hydrophilic film-based ethanol vapour-controlled release sachet (A), and interactions between water vapour molecules adsorbed into EVA as well as Nylon layers causing plasticization effects, subsequently causing higher permeation rates of ethanol vapour out from the sachet (B).

\subsubsection{Preparation of ethanol-controlled release sachets}

As conceptually shown in Figure 1-A and B, EVA and Nylon/PE were laminated through applying heat via a heating plate onto EVA film which was laid on top of the Nylon/PE one. Once heated, the EVA film will slightly melt and firmly attaches to the Nylon/PE film. The laminated film was designated as ENP, having 
$201.03 \mu \mathrm{m}$ thickness. The ENP film later was connected with Al/PE (an aluminium film laminated with polyethylene one; $80 \mu \mathrm{m}$ thickness) (Figure 1-B) as 3 side-sealed heat-sealed sachet. The filter paper $(5 \times 5 \mathrm{~cm})$ soaked with the ethanol liquid $(0.2 \mathrm{~mL}, 99 \% \mathrm{v} / \mathrm{v}$ Ethanol absolute EMSURE ${ }^{\circledR}$, Merck, Germany) was inserted into the sachet of which the open-end was immediately heatsealed. The sachet subsequently became 4-side-sealed form having a size of $6 \times 6 \mathrm{~cm}$. In addition to the sachet made from ENP film, the single EVA film layer was also formed as a sachet, through the same preparation. Both sachet types later were tested for ethanol vapour releases under different relative humidity levels. For further references extensively made in this work, the sachet of which its material comprised with either ENP or single EVA film was designated as ENP-based or EVA-based sachet, respectively.

\subsection{Tests of ethanol vapour releases from hydrophilic film-based sachets}

To test ethanol vapour releases from the sachets, experimental methods were modified from those reported by Lee (2003) for testing 1-methylcyclopropene (1-MCP) releases from sachets. In the present work, each sachet type (i.e. ENP-based or EVA-based sachet) was put in a glass beaker (i.e. one beaker for one sachet). The $250 \mathrm{~mL}$ glass beaker later was put in an aluminium foil bag together with an RH meter (Testo, Germany). The bag was then heat-sealed. The flow of humidified air later was introduced into the bag via a plastic tube where one end was connected with a needle inserted into the bag, whilst the other end of the tube was connected to the humidified air generator containing a salt solution (i.e., $\mathrm{Mg}\left(\mathrm{NO}_{3}\right)_{2} 6 \% \mathrm{w} / \mathrm{v}$ or $\left.\mathrm{MgCl}_{2} 8 \% \mathrm{w} / \mathrm{v}\right)$ or distilled water. After 15 mins which was a sufficient time for the air inside the bag to become well mixed, the tube was then pulled out from the bag. Holes created on the bag surface was immediately sealed using aluminium tape. The ethanol vapour concentration accumulated inside the aluminium bags were periodically measured using methods described by Utto et al. (2018). The gas sample $(1 \mathrm{~mL})$ was taken from the headspace using a Hamilton ${ }^{\circledR}$ gas-tight syringe. The sample thereafter was injected into the flame-ionized detector gas chromatogram (FID-GC; GC-2014 model, Shimadzu, Japan) equipped with Porapak Q (a packed column having a $2.0 \mathrm{~m}$ length as well as a $3.00 \mathrm{~mm}$ inner diameter). The FID-GC operational conditions were $250^{\circ} \mathrm{C}$ detector, and $150^{\circ} \mathrm{C}$ inlet temperatures. The column temperature was kept at $80^{\circ} \mathrm{C}$ for $30 \mathrm{~s}$, later its temperature was programed to increase with a rate of $10^{\circ} \mathrm{C} / \mathrm{min}$ until it reached $200^{\circ} \mathrm{C}$ and maintained for 3 mins. The carrier gas was helium (B.O.C. Gases, Thailand). Ethanol vapour concentration was reported in terms of $\mu \mathrm{L} / \mathrm{L}$. Releases of ethanol vapour from the sachets were tested at $10^{\circ} \mathrm{C}$ for 14 days to simulate the marketing condition under which the target horticultural commodity would be tested in further experiments with the prototype sachet.

\subsection{Tests of extents of water vapour uptakes by hydrophilic films}

Test films were kept in hermetical plastic jars containing salt solutions (as those aforementioned in 2.3) or distilled water, for humidifying headspaces. The film was hung above the solution using a stainless-steel wire where one end was connected to the lid. Weights of individual films were weighed periodically until constant. The generic exponential model (Equation (1)) was applied to predict empirical data using nonlinear regression analysis. Values of model coefficients of Equation (1) were identified by minimizing the sum of squared residuals using Microsoft Excel ${ }^{\circledR}$. Furthermore, statistical analyses were undertaken to evaluate differences between data obtained from Equation (1) prediction and empirical results, through $\mathrm{R}^{2}$ and root mean squares of errors (RMSE) following Yang and Chinnan (1988).

$$
A_{f i l m, s a t}^{u p p k}=k_{\text {film }}^{u p t k} \exp \left(b_{f i l m}^{u p t k} \cdot R H\right)
$$

where $A_{f i m, s a t}^{u \text { upt }}=$ water vapour uptake when the film became saturated with water vapour at a given relative humidity $(\mathrm{g} / \mathrm{g}), k_{f i m}^{u p t k}=$ exponential model coefficient $(\mathrm{g} / \mathrm{g})$, and $b_{f i l m}^{u p h}=$ exponential model coefficient (dimensionless), and $R H=$ relative humidity $(\%$ or $\mathrm{g} / \mathrm{g})$.

\subsection{Experiment design and statistical analysis}

This study was experimentally planned in accordance with a completely randomized design (CRD). For tests on ethanol vapour release from sachets, there were 2 treatments i.e. (1) ENP-based and (2) EVA-based film sachets, three replicates of individual treatments were tested. For tests on water vapour uptakes, there were 3 treatments in accordance with the films tested i.e., Nylon/PE, EVA and ENP films. Experimental data were statistically analysed in terms of descriptive statistics i.e., average and standard deviation as well as the values of both $\mathrm{R}^{2}$ and RMSE (as noted in 2.4) using Microsoft Excel $^{\circledR}$ (ver. 2010). The experiments were undertaken during October 2020-January-2021.

\section{Results and discussion}

3.1 Ethanol vapour releases from sachets under different relative humidity levels

Ethanol vapour concentrations in all systems continuously increased within $120 \mathrm{hrs}$ and reached their steady-state levels at the concentrations measured 
thereafter (Figure 2). Higher ethanol vapour concentrations were found in the EVA sachet systems, compared to those in the ENP sachet ones. The ENPbased sachets caused approximately $24 \mathrm{hr}$ delays in releases of ethanol vapour, whilst the EVA-based sachet instantly released ethanol vapour. Differences in release patterns, as well as concentration levels accumulated, were because of the film's property, namely film permeance to ethanol vapour (FPE) indicating extents of eases for which ethanol molecules can permeate through the film structure (Miyauchi et al., 1996; Utto et al., 2016). In our concurrent research project, FPE values of EVA were relatively higher than those of ENP given similar ethanol vapour concentrations (unpublished data). The delays noted among ENP sachets (Figure 2) importantly were explained by lower values of FPE of the ENP films, causing slower permeation rates through the film. Furthermore, since the thickness of the ENP film was more than that of the EVA, this subsequently reduces rates of ethanol permeation across the film. According to Fick's law of diffusion (Robertson, 2012), the film permeation rate has an inverse relationship with the film thickness i.e., the thicker film thickness, the lower rate would occur.

For a given sachet type, levels of ethanol vapour concentrations accumulated in headspaces were in positive relations to those of relative humidity (in Figure 2 ), indicating apparent effects of humidity on ethanol vapour release. The releases became faster under higher relative humidity levels, especially at $90-99 \% \mathrm{RH}$, causing higher concentrations accumulated in the headspaces. It could be observed that release rates and concentrations tested at $80-89 \%$ RH were slightly higher than those tested at $60-75 \% \mathrm{RH}$. These presumably could be attributed to different extents of water vapour absorbed into films under different humidity levels (further discussion was also presented in 3.2). Such differences could affect the plasticization effects that occurred in the polymeric structure. In the present work, both types of sachets contain the EVA layer, a highly hydrophilic film, therefore it can easily adsorb and interact with moisture leading to the plasticization effects as aforementioned (Robertson, 2012). Because the EVAbased sachet did not contain Nylon/PE layer, the plasticized film could facilitate ethanol vapour releases to a great extent, particularly under a high relative humidity level. These subsequently cause faster release rates and higher accumulation of ethanol vapour concentration (Figure 2). In contrast, the ENP-based sachet had a Nylon/PE layer in addition to the EVA one. The Nylon/PE film allows ethanol molecules to permeate at a slow rate (Utto et al., 2016). Although the ENPbased sachet had the plasticized EVA layer, the ethanol molecules had to permeate through the Nylon/PE film prior to reaching the EVA layer. Such phenomena could be the main reason for an underlying slower release as well as lower accumulation of ethanol vapour concentration in headspaces containing the ENP-based sachets. The experimental findings in the present work are similar to those reported by Utto et al. (2018). The sachet made of low-density polyethylene (LDPE) filmbased sachet could release ethanol vapour with faster rates compared to that made of Nylon/PE, subsequently causing higher ethanol vapour concentration accumulated in the package. The differences principally were attributed to the FPE value of the films of which LDPE had relatively higher than that of Nylon/PE (Utto et al., 2016).

\subsection{Extents of water vapour uptake by hydrophilic films}

As shown in Figure 2, we observed levels of ethanol vapour concentrations accumulated at $60-75 \% \mathrm{RH}$ and $80-89 \%$ RH were not significantly different (Figure 2). However, these were lower than those at $90-99 \% \mathrm{RH}$, in particular during $96 \mathrm{hrs}$. The experimental findings highlight the effects of humidity levels on ethanol vapour releases. We subsequently conducted experiments to

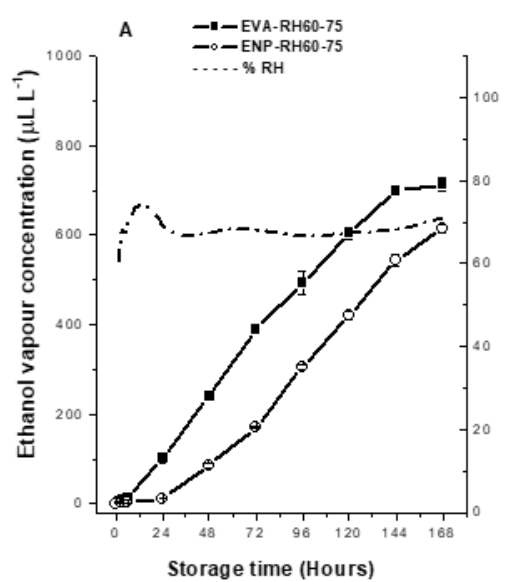

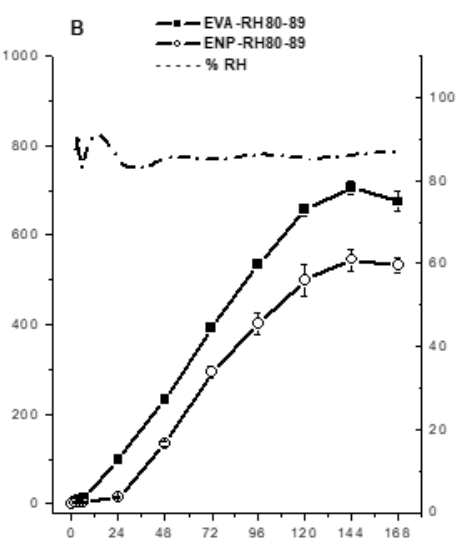

Storage time (Hours)

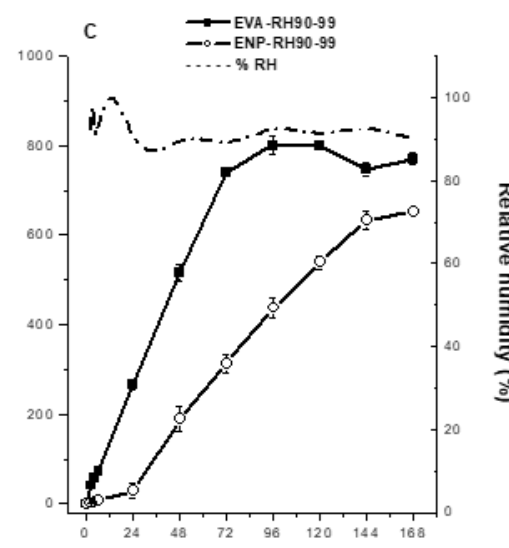

Storage time (Hours)

Figure 2. Changes of concentrations of ethanol vapour released from both EVA and ENP-based sachets kept under different relative humidity levels, at $10^{\circ} \mathrm{C}(\mathrm{n}=3$; average \pm standard deviation $)$ 

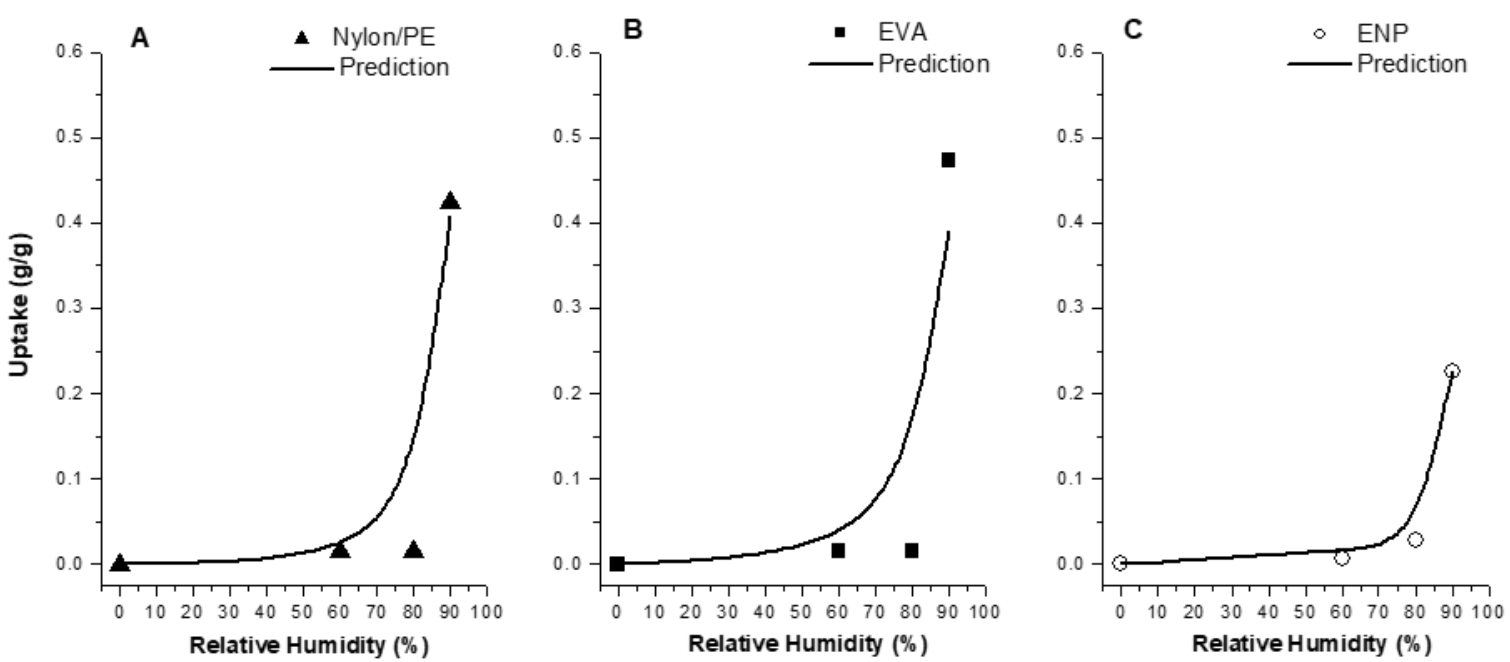

Figure 3. Extents of water vapour uptakes by hydrophilic films including Nylon/PE (A), EVA (B) and ENP (C) films (n=3) in relations to surrounding relative humidity levels, at $10^{\circ} \mathrm{C}$ (symbolic data). Solid lines were data of water vapour uptakes predicted Equation (1).

clarify such effects which were essentially assumed as results of different extents of water vapour uptakes by the films under varying relative humidity levels. In Figure 3, it could be observed that changes of water uptake extents were considered minimal under $<90 \%$ RH. However, the extents became exponentially increased when the humidity levels were $\geq 90 \% \mathrm{RH}$. The experimental results support the hydrophilic properties of both Nylon/PE and EVA films as well as the water vapour uptake by the films in relation to the RH levels. The water vapour uptakes predicted by Equation (1) well converged with the empirical ones $\left(\mathrm{R}^{2}\right.$ 0.92-0.99; RMSE 0.004-0.054) (Table 1). The statistical analyses suggest that the exponential model could be considered a suitable model to represent empirical data (Yang and Chinnan, 1988). In Table 1, values of Equation (1)'s coefficients estimated for the ENP film were higher than those for Nylon/PE and EVA. The information points out that the ENP film tends to absorb water vapour to a higher extent in particular when the RH levels were $\geq 80 \% \mathrm{RH}$ (Figure 3 ). These would partly be the results of two hydrophilic films laminated together. However, at $90 \% \mathrm{RH}$, the extent of water vapour uptake by the ENP film was lower than that individually found in both Nylon/PE and EVA. Such a lower extent could be postulated as result of clusters formed among water vapour molecules absorbed into the polymeric structures (Johansson and Leufvén, 1994), subsequently minimizing uptake as well as other related processes including diffusion through the

Table 1. Parameter estimated from Equation (1) utilized to predict water vapour uptake by hydrophilic films at $10^{\circ} \mathrm{C}$

\begin{tabular}{lcccc}
\hline \multicolumn{1}{c}{ Film } & $\begin{array}{c}k_{\text {film }}^{u p t k} \\
(\mathrm{~g} / \mathrm{g})\end{array}$ & $\begin{array}{c}b_{\text {film }}^{u p t k} \\
(\text { dimensionless) }\end{array}$ & $\mathrm{R}^{2}$ & RMSE \\
\hline Nylon/PE & $1.49 \times 10^{-6}$ & 0.14 & 0.95 & 0.03 \\
EVA & $1.20 \times 10^{-6}$ & 0.14 & 0.95 & 0.04 \\
ENP & 0.01 & 12.1 & 0.99 & 0.004 \\
\hline
\end{tabular}

eISSN: $2550-2166$ structure. Likewise, Marais et al. (2000) reported that clusters of water absorbed formed in polymeric structures of polyolefins caused lower water diffusion, subsequently slow permeation through the structures.

\section{Conclusion}

It could be concluded that surrounding humidity levels had significant effects on ethanol vapour releases from the hydrophilic film-based sachet. Laminating Nylon/PE with EVA film (or ENP film) could improve the film barrier to ethanol vapour causing possible delays of the ethanol vapour from the ENP-based sachet. Because the high humidity level, $\geq 90 \% \mathrm{RH}$, evidently facilitates ethanol vapour release from the prototype sachet, it could be expected that incorporations of the prototype sachet to passive MAP should provide benefits on microbial controls. Future works are required to test the sachet in the current commercial passive MAP which is currently used with fruit and vegetable, for optimizing to suit packaging and storage requirements of the products.

\section{Acknowledgements}

The researchers would like to express our appreciations to the National Metal and Materials Technology Center (MTEC), National Science and Technology Development Agency (NSTDA), Thailand for providing generous funding supports via the TGIST scholarship 2019, and Faculty of Agriculture, Ubon Ratchathani University, Thailand for providing supports on laboratory facilities and instruments.

\section{References}

Bai, J., Plotto, A., Spotts, R. and Rattanapanone, N. 
(2011). Ethanol vapor and saprophytic yeast treatments reduce decay and maintain quality of intact and fresh-cut sweet cherries. Postharvest Biology and Technology, 62(2), 204-212. http:// doi.org/10.1016/j.postharvbio.2011.05.010.

Choosung, P., Utto, W., Boonyaritthongchai, P., Wasusri, T. and Wongs-Aree, C. (2019). Ethanol vapor releasing sachet reduces decay and improves aroma attributes in mulberry fruit. Food Packaging and Shelf Life, 22, 100398. http://doi.org/10.1016/ j.fps1.2019.100398.

Fonseca, S.C., Oliveira, F.A. and Brecht, J.K. (2002). Modelling respiration rate of fresh fruits and vegetables for modified atmosphere packages: a review. Journal of Food Engineering, 52(2), 99-119. http://doi.org/10.1016/s0260-8774(01)00106-6.

Johansson, F. and Leufven, A. (1994). Food Packaging Polymer Films as Aroma Vapor Barriers at Different Relative Humidities. Journal of Food Science, 59(6), 1328-1331. http://doi.org/10.1111/j.13652621.1994.tb14708.x.

Kader, A.A., Zagory, D., Kerbel, E.L. and Wang, C.Y. (1989). Modified atmosphere packaging of fruits and vegetables. Critical Reviews in Food Science and Nutrition, 28(1), 1-30. http:// doi.org/10.1080/10408398909527490.

Kampawong, H., Utto, W. and Pruthtikul, R. (2018). Extending shelf life of fresh cherry tomatoes using ethanol vapour controlled release based active packages. presented at 1st Rajamangala Surin International Conference, p. 20-27. Thailand: Rajamangala University of Technology Isan, Surin Campus.

Lee, Y.S. (2003). Development of a 1Methylcyclopropene Delivery System to Control Tomato Ripening. Michigan: Michigan State University, USA.

Malakar, S., Kumar, N., Sarkar, S. and Mohan, R.J. (2020). Influence of Modified Atmosphere Packaging on the Shelf Life and Postharvest Quality Attributes of King Chili (Capsicum chinense Jacq.) during Storage. Journal of Biosystems Engineering, 45(4), 213-222. http://doi.org/10.1007/s42853-02000057-8.

Marais, S., Ngugen, C., Devallencourt, C., Metayer, M., Nguyen, T.U. and Schaetzel, P. (2000). Permeation of water through polar and nonpolar polymer and copolymers: Determination of the concentrationdependent diffusion coefficient. Journal of Polymer Science Part B Polymer Physics, 38(15), 1998-2008. https://doi.org/10.1002/1099-0488(20000801)

38:15<1998::AID POLB50>3.0.CO;2-A
Miyauchi, M., Nakanishi, Y. and Sagara, Y. (1996). Permeation of Water and Volatile Flavors through Packaging Films. Food Science and Technology International, 2(4), 217-222. http://doi.org/10.3136/ fsti9596t9798.2.217.

Robertson, G.L. (2012). Food Packaging: Principles and Practice, $3^{\text {rd }}$ ed. New York, USA: Taylor and Francis Group. https://doi.org/10.1201/b21347

Siracusa, V. (2012). Food Packaging Permeability Behaviour: A Report. International Journal of Polymer Science, 2012, 1-11. http:// doi.org/10.1155/2012/302029.

Utto, W., Mawson, J., Bronlund, J. and Wong, K. (2005). Active packaging technologies for horticultural produce. Food New Zealand, 5, 21-32.

Utto, W. (2014). Factors affecting release of ethanol vapour in active modified atmosphere packaging systems for horticultural products. Maejo International Journal of Science and Technology, 8 (1), 75-85. http://doi.org/10.14456/mijst.2014.7.

Utto, W., Pruthtikul, R., Malila, P., Noomhorm, A. and Bronlund, J.E. (2016). Concentration and Temperature Dependences of Effective Ethanol Vapor Permeance of Plastic Films Utilized in Controlled Release-Based Active Packaging for Horticultural Products. Key Engineering Materials, 718, 45-48. http://doi.org/10.4028/ www.scientific.net/kem.718.45.

Utto, W., Preutikul, R., Malila, P., Noomhorm, A. and Bronlund, J.E. (2018). Delaying microbial proliferation in freshly peeled shallots by active packaging incorporating ethanol vapour-controlled release sachets and low storage temperature. Food Science and Technology International, 24(2), 132144. http://doi.org/10.1177/1082013217735951.

Yang, C.C. and Chinnan, M.S. (1988). Modeling the Effect of $\mathrm{O}_{2}$ and $\mathrm{CO}_{2}$ on Respiration and Quality of Stored Tomatoes. Transactions of the ASAE, 31(3), 920-925. https://doi.org/10.13031/2013.30800 